\title{
A case of cholestatic hepatitis associated with histologic features of acute cholangitis
}

This article was published in the following Dove Press journal:

International Journal of General Medicine

22 November 2011

Number of times this article has been viewed

Hajime Takeuchi'
Toru Kaneko'
Toshikazu Otsuka'
Kumiko Tahara'
Tadashi Motoori'
Makoto Ohbu
Masaya Oda
Hiroaki Yokomori'
'Department of Internal Medicine;
${ }^{2}$ Division of Pathology, Kitasato
Medical Center Hospital, Kitasato
University, Saitama; ${ }^{3}$ Department of
Pathology, School of Allied Health
Sciences, Kitasato University,
Sagamihara, Kanagawa; ${ }^{4}$ Department
of Internal Medicine, Saitama
Social Insurance Hospital, Saitama;
${ }^{5}$ Organized Center of Clinical
Medicine, International University
of Health and Welfare, Sanno Hospital,
Tokyo, Japan

Tokyo, Japan
Correspondence: Hiroaki Yokomori Department of Internal Medicine, Kitasato University, Kitasato Institute Medical Center Hospital, 6-100 Arai, Kitamoto-shi, Saitama 364-850 I, Japan $\mathrm{Tel}+8 \mid 48593 \quad 1212$

Fax +8I 48593 I239

Email yokomori@insti.kitasato-u.ac.jp
Abstract: This report describes a case showing histologic features of acute cholangitis with an over-the-counter drug. A 48-year-old woman was diagnosed with general malaise and progressive jaundice. A thorough review of her medical history revealed that the patient had taken an over-the-counter drug, Pabron Gold ${ }^{\circledR}$, which she had used previously, that may have caused liver injury. Laboratory investigations revealed jaundice and liver dysfunction. Endoscopic retrograde cholangiography detected no extrahepatic biliary duct dilatation or stones. Liver biopsy indicated acute cholangitis involving neutrophils and eosinophils. Electron microscopy revealed fragmented nuclei, indicating that the degenerative bile duct-related epithelial cells were in an apoptotic process.

Keywords: liver injury, over-the-counter drug, histologic features, acute cholangitis, electron microscopy, Pabron Gold

\section{Introduction}

Drug-induced liver injury (DILI) is a rare condition. Reactions that result in DILI are regarded as idiosyncratic, occurring from therapeutic doses with a likelihood of occurrence in $1 / 1000$ to $1 / 100,000$ patients, with a pattern that is consistent for each drug and for each drug class. Idiosyncratic reactions are characterized by a variable delay or latency period of 5-90 days following initial ingestion of the drug. They are frequently fatal if the drug is taken continually, even after the onset of the reaction. ${ }^{1}$ In Japan, liver injury might be hepatocellular (59\%), mixed (20\%), or cholestatic $(20 \%){ }^{2}$ An examination of causal drugs during the periods 1997-2006 and 1989-1998 revealed antibiotics and antipyretic/analgesic/anti-inflammatory drugs to be among the top ranked in each period (14.3\% and 9.9\%, respectively, in 1997-2006), while dietary supplements and Chinese herbal medicines each showed an increase during 1997-2006 (10.0\% and $7.1 \%$, respectively), and over-the-counter drugs remained at similar levels during both periods (5.5\% in 1997-2006 and 5.8\% in 1989-1998). ${ }^{2}$ Repeated drug injections that have a broader spectrum of compounds and a personal history of previous reaction to a drug are common patterns among people with severe or prolonged liver injury. ${ }^{3-6}$

This report describes a case showing histologic features of acute cholangitis of cholestatic type associated with the over-the-counter drug Pabron Gold ${ }^{\circledR}$ (Taisho Pharmaceutical Co Ltd, Tokyo, Japan).

\section{Case report}

A 48-year-old woman was admitted to the authors hospital with progressive jaundice and general malaise. She had no history of significant illness, dietary or lifestyle 
modification, or alcohol or drug use. She started to develop persistent epigastric distress and general malaise 4 days before admission. A thorough review of her medical history showed that the patient had taken an over-the-counter drug, Pabron Gold (each tablet containing dihydrocodeine phosphate, $8 \mathrm{mg}$; di-methylephedrine hydrochloride, $20 \mathrm{mg}$; guaifenesin, $41.67 \mathrm{mg}$; acetaminophen, $300 \mathrm{mg}$; lysozyme hydrochloride, $20 \mathrm{mg}$; carbinoxamine maleate, $2.5 \mathrm{mg}$; anhydrous caffeine, $25 \mathrm{mg}$; bisibutiamine, $8 \mathrm{mg}$; and riboflavin, $4 \mathrm{mg}$ ), for upper respiratory inflammation. She took three tablets each day December 20-23, 2010, then January 4-6, 2011, and again January 21-23, 2011. She was admitted to the authors' hospital on February 6, 2 weeks after the last dose.

Before presentation at a local hospital on February 5, she had noticed jaundice with subsequent darkened urine and lighter-colored stools. She was referred to the authors' hospital for additional investigation of hyperbilirubinemia. On admission, physical examination showed severe mucocutaneous jaundice with a slightly distended abdomen. The liver was enlarged by $3 \mathrm{~cm}$ below the right coastal margin: firm, but not tender. She had no skin eruption or rash. Her body temperature was $36.6^{\circ} \mathrm{C}$ and her pulse rate was 70 beats $/ \mathrm{min}$. Respiration was 12 breaths $/ \mathrm{min}$. Blood pressure was $117 / 80 \mathrm{mmHg}$. Her height and weight were $156.5 \mathrm{~cm}$ and $62.9 \mathrm{~kg}$, respectively. Blood tests showed a white blood cell count of $5880 / \mu 1$ (neutrophils $67.4 \%$, lymphocytes $22.4 \%$, monocytes $7.8 \%$, eosinophils $7.8 \%$ ). Her red blood cell count was $377 \times 10^{4} / \mu 1$, with hemoglobin of $12.3 \mathrm{~g} / \mathrm{dL}$, platelets of $21.9 \times 10^{4} / \mathrm{mm}^{3}$, prothrombin time $100 \%$, and C-reactive protein of $4.42 \mathrm{mg} / \mathrm{d}$. Urinalysis results showed specific gravity $1.017 \mathrm{~g} / \mathrm{mL}, \mathrm{pH} 6.0$, sugar (-), protein (-), ketone (1+), bilirubin (3+), and urobilinogen $(+/-)$. Blood biochemical tests showed the following: total bilirubin $6.7 \mathrm{mg} / \mathrm{dL}$, direct bilirubin $5.2 \mathrm{mg} / \mathrm{dL}$, aspartate aminotransferase $182 \mathrm{IU} / \mathrm{L}$, alanine aminotransferase $376 \mathrm{IU} / \mathrm{L}$, lactate dehydrogenase $282 \mathrm{IU} / \mathrm{L}$, alkaline phosphatase $936 \mathrm{IU} / \mathrm{L}$, $\gamma$-glutamyl transferase $772 \mathrm{IU} / \mathrm{L}$, cholinesterase $377 \mathrm{U} / \mathrm{mL}$, total protein $8.7 \mathrm{~g} / \mathrm{dL}$, albumin $4.5 \mathrm{~g} / \mathrm{dL}$, total cholesterol $248 \mathrm{mg} / \mathrm{dL}$, triglycerides $171 \mathrm{mg} / \mathrm{dL}$, blood urea nitrogen $8.3 \mathrm{mg} / \mathrm{dL}$, creatinine $0.7 \mathrm{mg} / \mathrm{dL}$, and pancreatic enzymes within normal limits. Viral hepatitis serology was performed. Results were negative for hepatitis A virus, hepatitis B virus, hepatitis C virus, Epstein-Barr virus, and Cytomegalovirus. Other relevant data were the following: immunoglobulin (Ig) G $1907 \mathrm{mg} / \mathrm{dL}$, IgG4 $80.2 \mathrm{mg} / \mathrm{dL}$, IgM $95 \mathrm{mg} / \mathrm{dL}$, antinuclear autoantibody $\times 40$ (normal range: below $\times 40$ ), mitochondria M2 Ab, P-antineutrophil cytoplasmic antibody
$<3.5$ (negative), C-antineutrophil cytoplasmic antibody $<1.3$ (negative), soluble interleukin 2 receptor 294 (normal range: 145-466) U/mL, and ferritin 452 (normal range: 4.0-62) ng/dL (Table 1).

Ultrasonographic evaluation yielded no evidence of dilated intrahepatic or dilated extrahepatic biliary ducts. Computed tomography (axial image) revealed no mass lesion (Figure 1A). Endoscopic retrograde cholangiography (ERC) detected no stones and extrahepatic biliary duct dilatation (Figure 1B). Therefore, the impaired hepatic function was not caused by extrahepatic injury but by liver damage. Her recent use of Pabron Gold was suspected as the cause of the liver injury. A drug-induced lymphocyte stimulation test for Pabron Gold was negative. A needle liver biopsy was performed on the tenth hospital day. Histological examination showed the absence of fibrosis and regenerative nodules and the presence of spotty necrosis, inflammation, edema, bile canalicular cholestasis, and pigmented hepatocytes around the central vein (Figure 2A). The inflammatory infiltrate contained polynuclear neutrophils and a varying number of eosinophils. Interlobular bile duct destruction was observed in the portal tract (Figure 2B). Both hematoxylineeosine and diastase-digested periodic acid-Schiff showed intraepithelial neutrophilic infiltration in the interlobular bile duct (Figure 2C). Silver staining showed that the basement membrane of the bile duct was preserved, but the nuclear arrangement was irregular (Figure 2D). No evidence of portal fibrosis was found from Masson's trichrome stain (Figure 2E).

Immunohistochemical cytokeratin (CK) 7 staining was also investigated in this case; minimal ductular reaction was visible (Figure 2F). Tissues histologically stained with reticulin stain were assessed using ImageJ (v 1.44p; National Institutes of Health, Bethesda, MD), a semiautomatic image analysis system. The profiles of the objects to be examined were traced on a digitizer board at $\mathrm{x} 200$ magnification. Then measurements were performed as described previously. ${ }^{7}$ The bile duct/hepatic artery volume ratio was $1.303(n=14)$. These findings were consistent with histologic features of acute cholangitis and cholestatic type associated with drug-induced liver injury and without ductopenia.

Electron microscopy was performed to further investigate hepatocytic pigmentation and bile duct destruction. Deposition of electron-dense biliary substances together with condensed polymorphic and fragmented nuclei was observed, suggesting degenerative bile duct-related epithelial cell apoptotic processes (Figure 3A). Moreover, an electron micrograph showed a Canal of Hering partially 
Table I Patient's laboratory data

\begin{tabular}{|c|c|c|}
\hline \multicolumn{3}{|l|}{ Blood count } \\
\hline WBC & 5800 & $3300-9000 / \mu \mathrm{l}$ \\
\hline $\mathrm{Neu}$ & $67.44 \%$ & \\
\hline Lym & $22.4 \%$ & \\
\hline Mono & $7.8 \%$ & \\
\hline Eo & $7.8 \%$ & \\
\hline RBC & $3.77 \times 10^{4}$ & $380-500 \times 10^{4} / \mu 1$ \\
\hline $\mathrm{Hb}$ & 12.3 & $11.5-15.0 \mathrm{~g} / \mathrm{dL}$ \\
\hline $\mathrm{Plt}$ & $21.9 \times 10^{3}$ & $\left|40-340 \times 10^{3} / \mu\right|$ \\
\hline \multicolumn{3}{|l|}{ Coagulation system } \\
\hline PTINR & 1.12 & $0.85-1.15$ \\
\hline \multicolumn{3}{|l|}{ Blood chemistry } \\
\hline T-bil & 6.7 & $0.2-1.2 \mathrm{mg} / \mathrm{dL}$ \\
\hline D-bil & 5.2 & $0.0-0.2 \mathrm{mg} / \mathrm{dL}$ \\
\hline AST & 182 & $10-40 \mathrm{IU} / \mathrm{L}$ \\
\hline ALT & 376 & $5-45 \mathrm{IU} / \mathrm{L}$ \\
\hline LDH & 282 & | $20-240$ IU/L \\
\hline ALP & 936 & $100-325 \mathrm{IU} / \mathrm{L}$ \\
\hline$\gamma$-GTP & 772 & $<30 \mathrm{IU} / \mathrm{L}$ \\
\hline ChE & 377 & $200-452 \mathrm{IU} / \mathrm{L}$ \\
\hline TP & 8.7 & $6.7-8.3 \mathrm{~g} / \mathrm{dL}$ \\
\hline ALB & 4.5 & $3.8-5.3 \mathrm{~g} / \mathrm{dL}$ \\
\hline T-chol & 248 & $120-219 \mathrm{mg} / \mathrm{dL}$ \\
\hline TG & 171 & $30-149 \mathrm{mg} / \mathrm{dL}$ \\
\hline $\mathrm{Na}$ & 140 & |37-147 mEq/L \\
\hline K & 5.1 & $3.5-5.0 \mathrm{mEq} / \mathrm{L}$ \\
\hline $\mathrm{Cl}$ & 99 & $98-108 \mathrm{mEq} / \mathrm{L}$ \\
\hline CRP & 4.42 & $<0.3 \mathrm{mg} / \mathrm{dL}$ \\
\hline Glc & 97 & $70-109 \mathrm{mg} / \mathrm{dL}$ \\
\hline TSH & 0.821 & $0.436-3.8 \mu \mathrm{lU} / \mathrm{mL}$ \\
\hline FT4 & 0.87 & $1.0-1.7 \mathrm{ng} / \mathrm{dL}$ \\
\hline Thyroglobulin Ab & $0.6(+)$ & $<0.3 \mathrm{U} / \mathrm{mL}$ \\
\hline \multicolumn{3}{|c|}{ Serological examination } \\
\hline Igm-HAAb & $(-)$ & $<0.80$ \\
\hline $\mathrm{HBsAg}$ & $(-)$ & \\
\hline $\operatorname{lgm}-\mathrm{HBc} \mathrm{Ab}$ & $(-)$ & \\
\hline $\mathrm{HCV} A b$ & $(-)$ & \\
\hline HCV RNA & $<1.2$ & $<1.2 \log \mathrm{IU} / \mathrm{mL}$ \\
\hline EBV-VCA IgM & $<10$ & $<\times 10$ \\
\hline EBV-VCA IgG & $\times 320$ & $<\times 10$ \\
\hline EBV-EBNA & $\times 1600$ & $<\times 10$ \\
\hline $\lg M \mathrm{CMV}$ & $(-)$ & 0.8 \\
\hline IgMHEV & $(-)$ & \\
\hline $\lg G$ & 1907 & $870-1700 \mathrm{mg} / \mathrm{dL}$ \\
\hline $\lg G 4$ & 80.2 & $4.8-105.0 \mathrm{mg} / \mathrm{dL}$ \\
\hline $\lg M$ & 95 & $46-260 \mathrm{mg} / \mathrm{dL}$ \\
\hline ANA & $\times 40$ & $<\times 40$ \\
\hline Mitochondria M2Ab & $<5.0(-)$ & $<7.0$ \\
\hline P-ANCA & $<3.5(-)$ & $<3.5 \mathrm{U} / \mathrm{mL}$ \\
\hline C-ANCA & $<1.3(-)$ & $<9.0 \mathrm{U} / \mathrm{mL}$ \\
\hline slL-2R & 294 & $124-466 \mathrm{U} / \mathrm{mL}$ \\
\hline Feritin & 452 & $4.0-62.2 \mathrm{ng} / \mathrm{dL}$ \\
\hline \multicolumn{3}{|l|}{ DLST } \\
\hline Pablon & 149 & $<179 \%$ \\
\hline \multicolumn{3}{|l|}{ HLA typing } \\
\hline$A^{*}$ & 02:01:01 & 24:02:01 \\
\hline $\mathrm{B}^{*}$ & 40:02:01 & \\
\hline
\end{tabular}

(Continued)
Table I (Continued)

\begin{tabular}{lll}
\hline$C^{*}$ & $03: 04: 01$ & \\
DRBI $^{*}$ & $11: 01: 01$ & $14: 01: 01$ \\
DQBI $^{*}$ & $03: 01: 01$ & $05: 03: 01$ \\
DPBI $^{*}$ & $02: 01: 02$ & $02: 02$ \\
DQAI $^{*}$ & $01: 04$ & $05: 05$
\end{tabular}

Abbreviations: WBC, white blood cells; Neu, neutrophils; Lym, lymphocytes; Mono, monocytes; Eo, eosinophils; RBC, red blood cells; Hb, hemoglobin; Plt, platelets; PTINR, prothrombin time international normalized ratio; T-bil, total bilirubin D-bil, direct bilirubin; AST, aspartate transaminase; ALT, alanine transferase; LDH, lactate dehydrogenase; ALP, alkaline phosphatase; $\gamma$-GTP, $\gamma$-glutamyl transpeptidase; ChE, cholinesterase; TP, total protein; ALB, albumin; T-chol, total cholesterol; TG, triglyceride; Na, sodium; K, potassium; Cl, chloride; CRP, C-reactive protein; Glc, glucose; TSH, thyroid stimulating hormone; FT4, free thyroxine; Ab, antibody; Ig, immunoglobulin; $\mathrm{HBsAg}$, hepatitis $B$ virus antigen; HCV-Ab, hepatitis $C$ virus antibody; HCV-RNA, hepatitis C virus RNA; EBV, Epstein-Barr virus; VCA, virus capsid antigen; EBNA, Epstein-Barr virus nuclear antigen; CMV, cytomegalo virus; HEV, Hepatitis E Virus, ANA; anti-nuclear antibody; M2 Ab, anti-mitochondrial antibody; P-ANCA, perinuclear anti-neutrophil cytoplasmic antibody; C-ANCA, cytoplasmic anti-neutrophil cytoplasmic antibody; sIL-2R, serum-soluble interleukin-2 receptor; DLST, drug lymphocyte stimulation test HLA, human leukocyte antigen.

lined by hepatocytes that were markedly dilated with loss of microvilli and dense deposition of biliary substances (Figure 3B and C). A remarkably dilated bile canaliculus was observed between two hepatocytes that showed complete loss of microvilli and heavy deposition of biliary substances (Figure 3B).

The drug-induced hepatitis score ${ }^{8}$ was 4: "probable." In this patient, symptoms and liver function improved after discontinuation of Pabron Gold (Figure 4).

\section{Discussion}

A search of the Japanese literature (JMEDPlus) and international literature (MEDLINE) yielded similar results of elevated hepatic transaminases associated with Pabron Gold. ${ }^{9}$ The reported liver injury was a mixed type.

The cholestatic jaundice observed in the patient discussed can be ascribed to the over-the-counter drug Pabron Gold for the following five reasons: (1) the patient had no prior history of disease of the liver or biliary tract; (2) no circumstantial
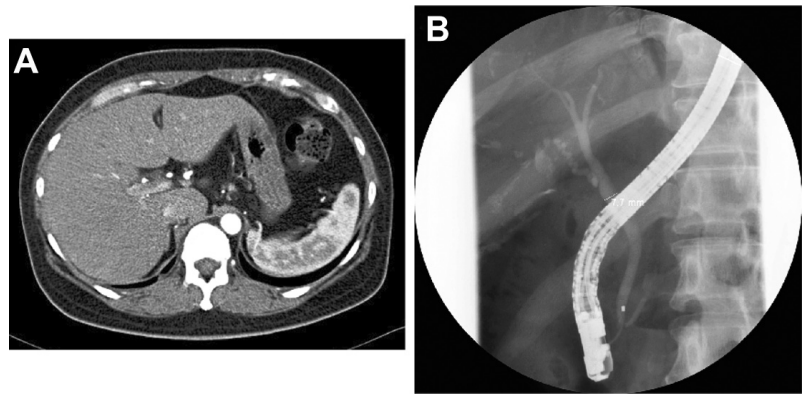

Figure I Computed tomography (axial image, arterial phase) and endoscopic retrograde cholangiography findings. (A) Computed tomography imaging shows no mass lesion. (B) endoscopic retrograde cholangiography shows no stones in common bile duct and no extrahepatic biliary duct dilatation. 


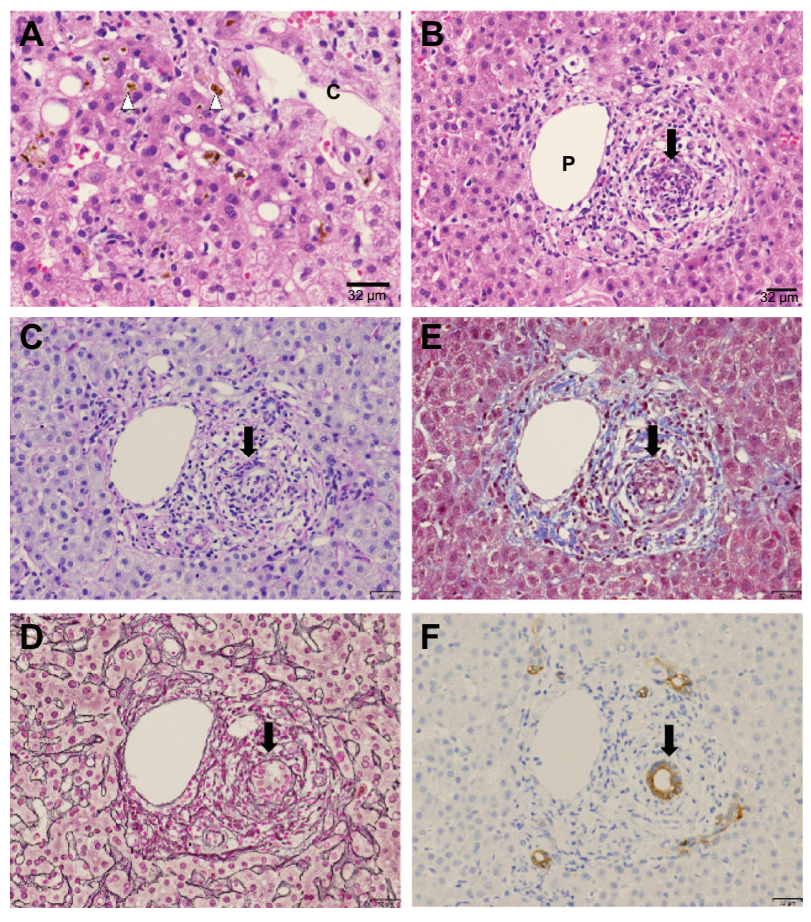

Figure 2 Light microscopic findings of liver biopsy. (A) Bile canalicular cholestasis findings showing edematous and pigmented hepatocytes around the central vein (arrowheads). "C" denotes the central vein. (B) Inflammatory infiltrate is made of polynuclear neutrophils and a varying number of eosinophils. Interlobular bile duct destruction is present in the portal tract. The arrow indicates destructive cholangitis. "P" denotes the portal vein. (C) HE and diastase-digested periodic acid-Schiff show intraepithelial neutrophilic infiltration in the interlobular bile duct. (D) Silver staining shows that basement membrane of the bile duct is preserved, but the nuclear arrangement is irregular. (E) Masson's trichrome staining yields no evidence of portal fibrosis. (F) Cytokeratin 7 immunostaining shows positive cytoplasmic expression in the bile duct.

or serological evidence indicated viral hepatitis; (3) a test for antimitochondrial antibodies was negative; (4) obstruction of the common bile duct was improbable because ERC was normal and no disorder suggestive of biliary tract obstruction was observed following the appearance of jaundice; and (5) jaundice developed 2 weeks after starting Pabron Gold, which disappeared promptly after withdrawal of the drug.

In the case presented, the toxic metabolites of the components of Pabron Gold might have caused injury to the bile duct epithelium.

The pathophysiology and mechanisms of DILI are still being investigated. They include both hepatocellular and extracellular mechanisms. Firstly, the parent drug, or, more frequently, its reactive metabolite, causes initial injury through direct cell stress, direct mitochondrial inhibition, or specific immune reactions such as major histocompatibility complex class II presentation of haptenated peptides to T cells. Second, the initial injury might induce mitochondrial permeability transition (MPT). Direct cell stress causes MPT via the intrinsic pathway
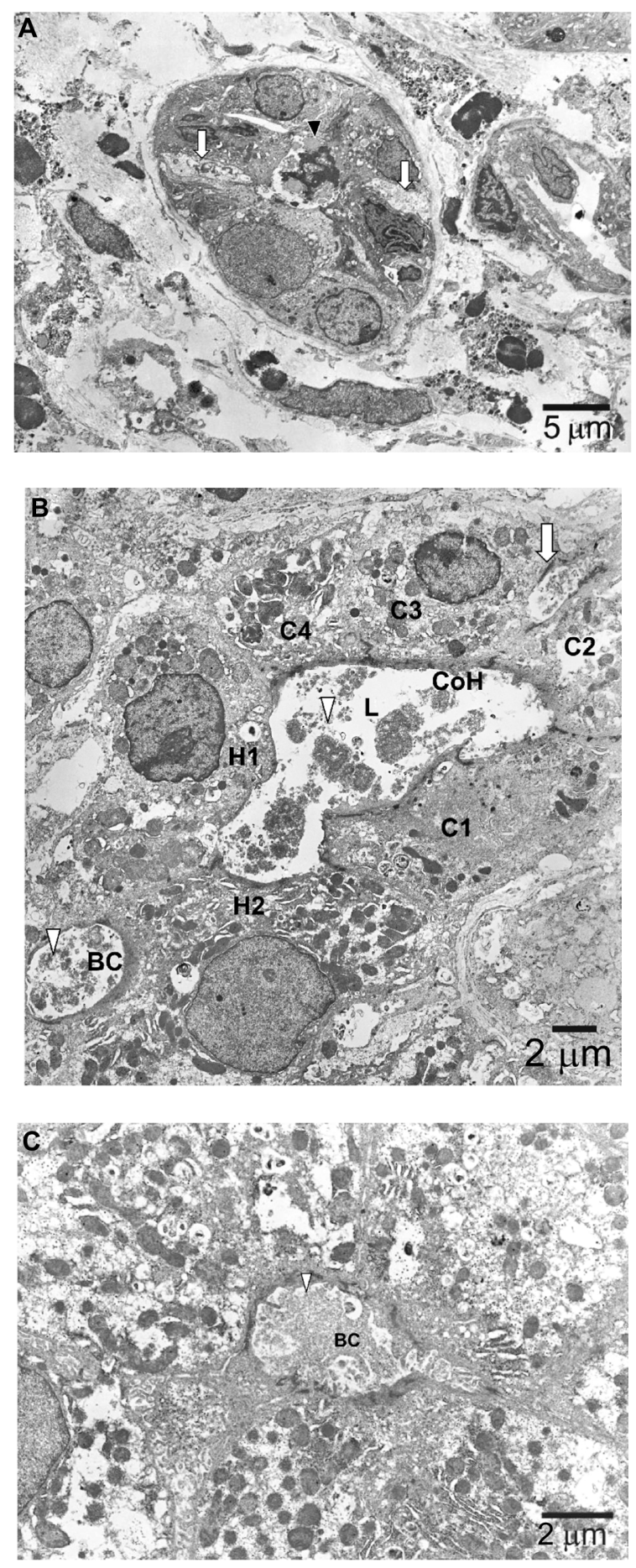

Figure 3 Electron microscopic findings. (A) Degenerative bile duct-related epithelial cells (arrowhead) are in an apoptotic process, as inferred from the appearance of condensed polymorphic and fragmented nuclei. The intercellular space adjacent to this degenerative epithelium is remarkably dilated (arrow), implying that bile substances are regurgitated from the lumen to the abluminal side. (B) A canal of Hering $(\mathrm{CoH})$ with markedly dilated lumen $(\mathrm{L})$ and loss of microvilli is lined by two hepatocytes $\left(\mathrm{HI}\right.$ and $\left.\mathrm{H}_{2}\right)$ and four cholangiocytes $(\mathrm{Cl}-\mathrm{C} 4)$ containing deposits of electron-dense biliary substances (arrowhead). The intercellular space adjacent to epithelium is dilated (arrow). Between the two hepatocytes $(\mathrm{HI}$ and $\mathrm{H} 2$ ) is a remarkably dilated bile canaliculus (BC) showing complete loss of microvilli and heavy deposition of biliary substances (arrow). (C) This electron micrograph shows a pseudo-bile ductule, the lumen of which is lined by six hepatocytes containing bile substances. The adjacent bile canaliculus (BC) is dilated with loss of microvilli and deposit of bile substances. The arrow indicates deposition of biliary substances. 


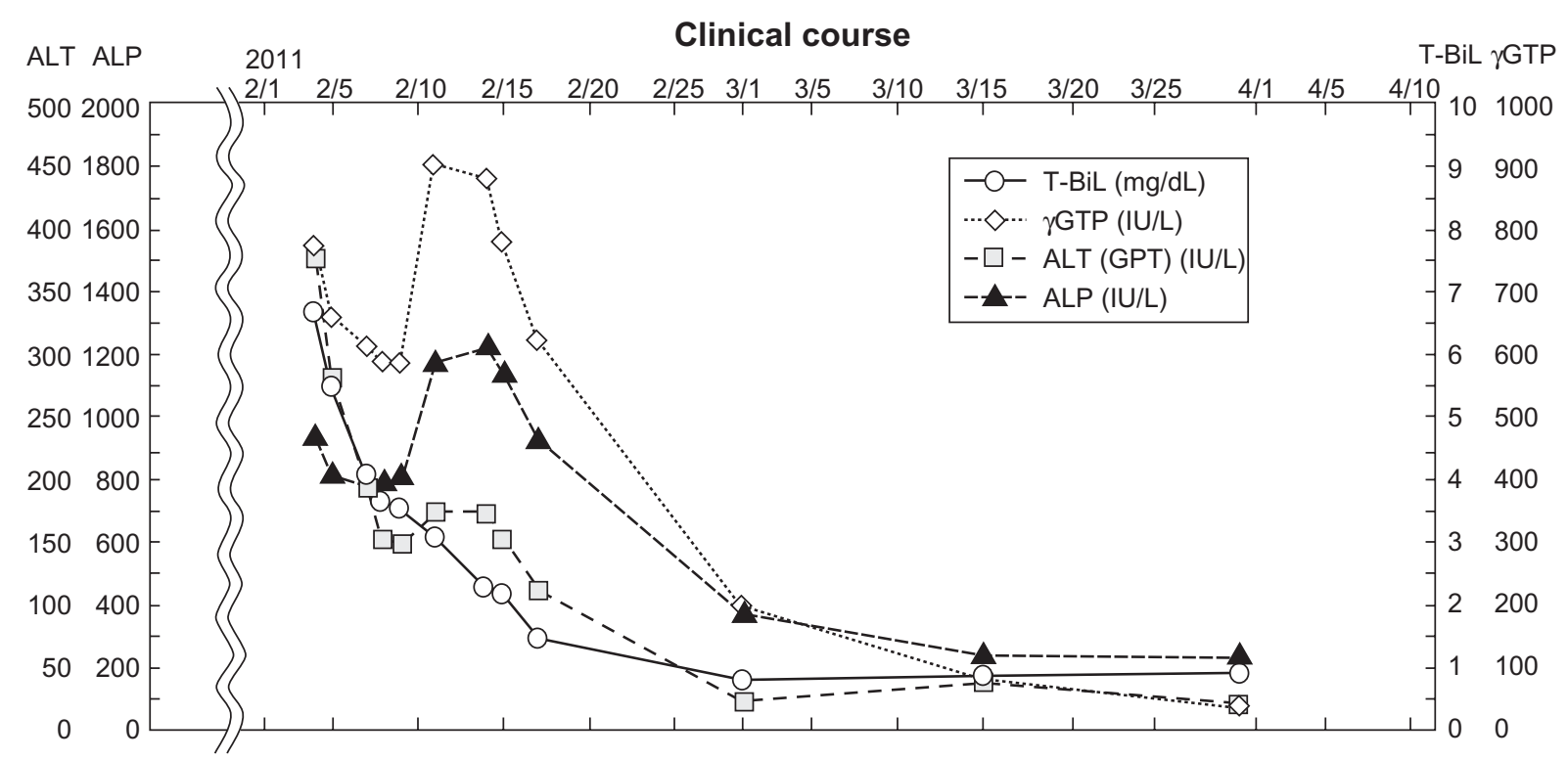

Figure 4 Clinical course.

Abbreviations: ALT, alanine transferase; ALP, alkaline phosphatase; T-bil, total bilirubin; $\gamma$-GTP, $\gamma$-glutamyl transpeptidase; GPT, gutamicpruvate transaminase.

that involves activation of intracellular stressor cascades and proapoptotic proteins. Third, MPT induces apoptosis or necrosis, depending on the availability of adenosine- 5 'triphosphate. Toxic metabolites excreted in bile might cause injury to the bile duct epithelium. Cell injury, gut-derived endotoxin, or their combination activates Kupffer cells and recruits neutrophils into the liver. ${ }^{10,11}$ In this case, acetaminophen - a component of Pabron Gold - cytochrome P450, family 2, subfamily E, polypeptide CYP2E1, plays an important role in the cytochrome P450 pathway of acetaminophen metabolism. ${ }^{12}$ Changes in cholangiocyte microvillus architecture are prominent in druginduced cholestasis. Large intrahepatic bile ducts express CYP2E1. They might be more sensitive to damage by drugs metabolized by this enzyme. ${ }^{13}$

In this case, the authors found that acute drug-induced cholangitis - diagnosed from laboratory data and liver biopsy findings - was associated with an over-the-counter drug. Acute cholangitis has been associated with several agents including allopurinol, carbamazepine, hydralazine, and sulindac. ${ }^{14-17}$ These observations suggest that such lesions are either specific to or significant for bile duct damage that is characteristic of drug-induced hepatic injury. Many such changes might reflect bile flow disturbance.

Several recent reports have described a strong genetic association between the human leukocyte antigen (HLA) allele and susceptibility to drug hypersensitivity. The genetic associations might be drug-specific, such as HLA-B1502 with carbamazepine-induced Stevens-Johnson syndrome, HLAB5701 with abacavir hypersensitivity, and HLA-B5801 with allopurinol-induced severe cutaneous adverse reactions. ${ }^{18}$ The high sensitivity and specificity of some markers provides a plausible basis for developing tests to identify individuals who are at risk for drug hypersensitivity. A patient's unique immune response is likely to play a role in the intensity and duration of injury because certain HLA haplotypes have been found to be markedly overrepresented in patients who develop drug-induced cholestatic hepatitis. ${ }^{19,20}$ Based on HLA-typing results for this patient (Table 1), a genetic association with drug-induced hepatitis is unlikely, as described in several reports in the aforementioned literature.

The patient's medical history revealed that she had started taking the over-the-counter drug Pabron Gold intermittently, for three short durations ( 3 days each) during the 6 weeks before admission, suggesting that the liver damage had occurred over a long period. Re-administration of the suspect drug during possible drug-induced liver injury can result in fatality or severe liver injury. Another survey has revealed that most rechallenge liver events occur within 1 month of the initial liver injury event. ${ }^{2}$ Mitochondrial impairment is a key mechanism of rechallenge injury, with a possible contribution from reactive metabolites.

The patient suffered no bacterial infection. She did not complain of fever, cough, localized redness, heat, swelling, or pain. The infection started on December 20, when treatment with Pabron Gold was started, though it is possible that the infection began even earlier. Treatment ended on January 23 , indicating use of the medication for more than 4 weeks. A viral infection usually lasts 1-2 weeks. A longer duration 
might signify bacterial complication. Hospitalization began 2 weeks after the Pabron Gold treatment. Presumably, the underlying disease continued. The high value of C-reactive protein suggests a bacterial infection. ${ }^{21}$ It was inferred that these histologic features of acute cholangitis were accompanied with bacterial infection.

During hospitalization, alkaline phosphatase initially declined and then started to increase, resulting in a second peak. This is not compatible with DILI, but instead suggests a drug-independent cause. ${ }^{22}$ On admission, the diagnostic procedures performed by endoscopic retrograde cholangiopancreatography in this case included a balloon "sweep" of the common duct. Mild cholangitis was complicated by alkaline phosphatase. ${ }^{23}$

"Ductopenia" refers to the absence of interlobular bile ducts from within the portal tracts. ${ }^{24}$ Multiple causes have been identified including infection, malignancy, autoimmune conditions, and adverse effects of medications.

The diagnosticyield can be increased by immunostaining with CK7, which identifies biliary elements. Immunohistochemical CK7 staining was used in this case. The analysis facilitated the identification of bile ducts in portal tracts with dense inflammation where the bile duct was obscured and showed well-preserved bile ducts.

Drug-specific genetic screening tests might prevent these diseases, which can be catastrophic. The capacity of current instruments to assess the causality of DILI might be enhanced by a combination of expert opinions. Efforts are underway to establish reliable DILI biomarkers.

\section{Disclosure}

The authors declare no conflicts of interest in this work.

\section{References}

1. Lee WM. Drug-induced hepatotoxicity. $N$ Engl J Med. 2003;349(5): 474-485.

2. Takikawa H. Recent status of drug-induced liver injury and its problems in Japan. JMAJ. 2010;53(4):243-247.

3. Bénichou C. Criteria of drug-induced hepatic disorders. Report of an international consensus meeting. J Hepatol. 1990;11(2):272-276.

4. Andrade RJ, Lucena MI, Fernández MC, et al. Drug-induced liver injury: an analysis of 461 incidences submitted to the Spanish registry over a 10-year period. Gastroenterology. 2005;129(2):512-521.

International Journal of General Medicine

\section{Publish your work in this journal}

The International Journal of General Medicine is an international, peer-reviewed open-access journal that focuses on general and internal medicine, pathogenesis, epidemiology, diagnosis, monitoring and treatment protocols. The journal is characterized by the rapid reporting of reviews, original research and clinical studies across all disease areas.
5. Papay JI, Clines D, Rafi R, et al. Drug-induced liver injury following positive drug rechallenge. Regul Toxicol Pharmacol. 2000;54(1): 84-90.

6. Hunt CM. Mitochondrial and immunoallergic injury increase risk of positive drug rechallenge after drug-induced liver injury: a systematic review. Hepatology. 2001;52(6):2216-2222.

7. Casali AM, Siringo S, Sofia S, Bolondi L, Di Febo G, Cavalli G. Quantitative analysis of intrahepatic bile duct component in normal adult human liver and in primary biliary cirrhosis. Pathol Res Pract. 1994;190(2):201-206.

8. Takikawa H. Recent status of drug-induced liver injury. Hepatol Res. 2009;39(1):1-6.

9. Tanimoto H, Nomura H. A case of bisferiens fluctuation associated with unknown acute liver injury. Japanese Journal of Clinical and Experimental Medicine. 2009;86:110-111. Japanese.

10. Russmann S, Jetter A, Kullak-Ublick GA. Pharmacogenetics of drug-induced liver injury. Hepatology. 2010;52(2):748-761.

11. Jaeschke H, Gores GJ, Cederbaum AI, Hinson JA, Pessayre D, Lemasters JJ. Mechanisms of hepatotoxicity. Toxicol Sci. 2002;65(2): 166-176.

12. Manyike PT, Kharasch ED, Kalhorn TF, Slattery JT. Contribution of CYP2E1 and CYP3A to acetaminophen reactive metabolite formation. Clin Pharmacol Ther. 2000;67(3):275-282.

13. LeSage GD, Glaser SS, Marucci L, et al. Acute carbon tetrachloride feeding induces damage of large but not small cholangiocytes from BDL rat liver. Am J Physiol. 1999;276 (5 Pt 1):G1289-G1301.

14. Swank LA, Chejfec G, Nemchausky BA. Allopurinol-induced granulomatous hepatitis with cholangitis and a sarcoid-like reaction. Arch Intern Med. 1978;138(6):997-998.

15. Larrey D, Hadengue A, Pessayre D, Choudat L, DeGott C, Benhamou JP. Carbamazepine-induced acute cholangitis. Dig Dis Sci. 1987;32(5): 554-557.

16. Myers JL, Augur NA Jr. Hydralazine-induced cholangitis. Gastroenterology. 1984;87(5):1185-1188.

17. Lerche A, Vyberg M, Kirkegaard E. Acute cholangitis and pancreatitis associated with sulindac (clinoril). Histopathology. 1987;11(6): 647-653.

18. Chung WH, Hung SI, Chen YT. Human leukocyte antigens and drug hypersensitivity. Curr Opin Allergy Clin Immunol. 2007;7(4): 317-323.

19. Hautekeete ML, Horsmans Y, Van Waeyenberge C, et al. HLA association of amoxicillin-clavulanate-induced hepatitis. Gastroenterology. 1999;117(5):1181-1186.

20. Reau NS, Jensen DM. Vanishing bile duct syndrome. Clin Liver Dis. 2008;12(1):203-217.

21. Clyne B, Olshaker JS. The C-reactive protein. J Emerg Med. 1999;17(6):1019-1025.

22. Bénichou C, Danan G, Flahault A. Causality assessment of adverse reactions to drugs - II. Original model for validation of drug causality assessment methods: case reports with positive rechallenge. $J$ Clin Epidemiol. 1993;46(11):1331-1336.

23. Loperfido S, Angelini G, Benedetti G, et al. Major early complications from diagnostic and therapeutic ERCP: a prospective multicenter study. Gastrointest Endosc. 1998;48:1-10.

24. Harrison RF, Patsiaoura K, Hubscher SG. Cytokeratin immunostaining for detection of biliary epithelium: its use in counting bile ducts in cases of liver allograft rejection. J Clin Pathol. 1994;47(4):303-308.

\section{Dovepress}

A key focus is the elucidation of disease processes and management protocols resulting in improved outcomes for the patient.The manuscript management system is completely online and includes a very quick and fair peer-review system. Visit http://www.dovepress.com testimonials.php to read real quotes from published authors. 